\title{
Left behind: widening disparities for males and females in US county life expectancy, 1985-2010
}

\author{
Haidong Wang, Austin E Schumacher, Carly E Levitz, Ali H Mokdad and Christopher JL Murray
}

\begin{abstract}
Background: The United States spends more than any other country on health care. The poor relative performance of the US compared to other high-income countries has attracted attention and raised questions about the performance of the US health system. An important dimension to poor national performance is the large disparities in life expectancy.

Methods: We applied a mixed effects Poisson statistical model and Gaussian Process Regression to estimate age-specific mortality rates for US counties from 1985 to 2010. We generated uncertainty distributions for life expectancy at each age using standard simulation methods.
\end{abstract}

Results: Female life expectancy in the United States increased from 78.0 years in 1985 to 80.9 years in 2010, while male life expectancy increased from 71.0 years in 1985 to 76.3 years in 2010. The gap between female and male life expectancy in the United States was 7.0 years in 1985, narrowing to 4.6 years in 2010. For males at the county level, the highest life expectancy steadily increased from 75.5 in 1985 to 81.7 in 2010, while the lowest life expectancy remained under 65. For females at the county level, the highest life expectancy increased from 81.1 to 85.0, and the lowest life expectancy remained around 73. For male life expectancy at the county level, there have been three phases in the evolution of inequality: a period of rising inequality from 1985 to 1993, a period of stable inequality from 1993 to 2002, and rising inequality from 2002 to 2010. For females, in contrast, inequality has steadily increased during the 25-year period. Compared to only 154 counties where male life expectancy remained stagnant or declined, 1,405 out of 3,143 counties (45\%) have seen no significant change or a significant decline in female life expectancy from 1985 to 2010. In all time periods, the lowest county-level life expectancies are seen in the South, the Mississippi basin, West Virginia, Kentucky, and selected counties with large Native American populations.

Conclusions: The reduction in the number of counties where female life expectancy at birth is declining in the most recent period is welcome news. However, the widening disparities between counties and the slow rate of increase compared to other countries should be viewed as a call for action. An increased focus on factors affecting health outcomes, morbidity, and mortality such as socioeconomic factors, difficulty of access to and poor quality of health care, and behavioral, environmental, and metabolic risk factors is urgently required.

\section{Background}

United States life expectancy at birth ranks 40th for males and 39th for females across 187 countries in the world in 2010 [1]. Given that the US spends more than any other country on health care [2-5] the poor relative performance of the US compared to other high-income countries has attracted increasing attention [6,7]. An important dimension to poor national performance is the large disparities

\footnotetext{
* Correspondence: mokdaa@u.washington.edu

Institute for Health Metrics and Evaluation, University of Washington, 2301 5th Avenue, Suite 600, Seattle, WA 98121, USA
}

in life expectancy and other metrics of mortality across populations within the US [8-12]. Racial and ethnic disparities as well as socio-economic disparities are large [13-15]. Multiple studies have demonstrated large variation in life expectancy across US counties [9]. Understanding large disparities in life expectancy within the US is important in its own right but may also provide insights into poor national performance.

Past evidence has investigated disparities in life expectancy at birth in the US. Ezzati et al. [8] reported not only that there were large disparities in life expectancy across

\section{Biomed Central}

(c) 2013 Wang et al.; licensee BioMed Central Ltd. This is an Open Access article distributed under the terms of the Creative Commons Attribution License (http://creativecommons.org/licenses/by/2.0), which permits unrestricted use, distribution, and reproduction in any medium, provided the original work is properly cited. 
counties in the US but from 1983 to 1999, female life expectancy fell in 180 counties and male life expectancy fell in 11 counties. Kulkarni et al. [11] reported that from 2000 to 2007, many US counties fell increasingly behind the levels achieved in high-income countries with the best outcomes. Kindig and Cheng [16] found evidence that mortality increases occurred from 1992-1996 to 2002-2006 for females in $42 \%$ of US counties. These reversals for females in life expectancy are cause for broad concern especially coming on top of large preexisting disparities in the US. Speculation on the causes of these reversals include the impact of tobacco consumption in females, rising levels of obesity, and associations in rates of change with a range of socio-economic factors [16]. Tracking the evolution of US disparities following the 2008 financial crisis is important, especially for females.

In this paper, we examine trends in life expectancy at the county level from 1985 to 2010 . We take advantage of the release of the 2010 Census age structure by county and updates for the intercensal period 2000 to 2010. Further, demographic estimation methods that more accurately reflect uncertainty have been recently widely applied [1] and have been incorporated into this study. Combined with new county mortality data through 2010, we are able to examine long-term and recent trends in county life expectancy for males and females.

\section{Methods}

We applied a statistical model to estimate age-specific mortality and life expectancy by age for US counties for the years 1985 to 2010, the last year with available mortality data at the county level. Our methodology requires five years of mortality data prior to each year estimated to make robust estimates. In addition, we need a set of counties or county aggregates that we can map and match to prior years in order to estimate a coherent time trend. These requirements mean that we are only able to estimate a county time series from 1985 to 2010.

\section{Modeling approach}

Estimating health outcomes for small areas is challenging as researchers are faced with large stochastic fluctuations due to small numbers of events or small numbers sampled. Commonly used methods to deal with these issues include pooling multiple years of data, borrowing strength across geospatial units, or using structured relationships with covariates [17]. Kulkarni et al. proposed a method for county life table estimation that integrates these three approaches [11], which we use here. Briefly, we used a mixed effects Poisson regression with time, geospatial, and covariate components.
The model is specified below:

$$
\begin{aligned}
\ln y_{r j t}= & \ln P_{r j t}+\beta_{0}+\beta_{1} \cdot \text { income }_{j t}+\beta_{2} \cdot \text { education }_{j t} \\
& +\beta_{3} \cdot \sigma_{\text {post }_{j}}+\beta_{4} \cdot \text { race }_{j t}+\left(\beta_{5}+\gamma_{j}\right) \cdot \text { time }_{t}+\mu_{j} \\
& +\varepsilon_{r j t}
\end{aligned}
$$

where yrjt and $P_{i j t}$ are the death count and population for race $r$ within county $j$ in year $t$. Incomejt is county per capita income for year $t$. Educationjt is the percent of adults within county $j$ having completed high school in each year. Race $_{j t}$ is a categorical variable for three race groups (white, black, and other). Asians and Native Americans were grouped into a single category to reduce the sensitivity of the model to known racial miscoding in population and death counts. opostj is the geospatial component, calculated as the average of the posterior model county random intercept for counties adjacent to county $j$ to account for residual spatial patterns. The values for $\sigma p o s t j$ are derived from running as a prior step the same model without the geospatial component to derive the posterior values of the county random effect. $\mu j$ is the posterior value of the county random intercept. Time $_{t}$ is the calendar year of mortality, and $\gamma j$ is a random slope on time for each county. This specification allows mortality in each county to have a unique trend. The county population size affects the contribution of the random components on death counts, leading to more emphasis on recorded death counts when predicting mortality for larger counties. The model was estimated separately by sex and five-year age groups because the magnitude of the county random effect varies by age. Because larger counties have observed age-specific death rates with narrower uncertainty intervals than derived from the model, we use the output of the mixed effects logistic regression of counties with non-zero death counts in all years for an age-sex group over the entire 19852010 period as a prior mean function for a Gaussian Process Regression where hyper-parameters were adapted from the those used by Wang et al. [1] for high-income countries. The effect of this step is to more accurately reflect the uncertainty in age-specific death rates in large counties.

The outcome of the analysis is a predicted age-, sex-, and race-specific death count for each county in the year of analysis. We used these counts, together with corresponding population figures, to calculate sex-specific life expectancy for each county. We used the method proposed by Wang et al. [1] to estimate the years lived in the terminal age group of the life table. With an increasing proportion of the population surviving to older age groups, accurately estimating age-specific mortality rate in people 85 or older is becoming crucial for estimating life expectancy at birth accurately. When we examine both the mean and uncertainty interval of the relative 
error in predicted age-specific mortality rates, the method developed by Wang et al. has been shown to provide results with much less bias when comparing to other widely used extrapolation methods [1].

To produce estimates for a given calendar year, we used data for that year and the five years prior to estimate the mixed effects Poisson regression. Uncertainty in county life expectancy was calculated using simulations by drawing repeatedly from the posterior distributions of the sex-, race-, age-, and county-specific death counts if the age-sex group in a county did not meet the criteria for Gaussian Process Regression and by Markov Chain Monte Carlo methods if it did meet the criteria.

We used mortality data, including county of residence, sex, race, age, and year of death from the National Center for Health Statistics (NCHS). County population denominators broken down by age, race, sex, and year were taken from the National Census Bureau for years prior to 1990 and from NCHS bridged-race population estimates otherwise. Our estimates of per-capita income were taken from the US Bureau of Economic Analysis. The series was deflated to generate real income per capita using GDP deflators provided by the World Bank. Educational attainment was based on census data from 1980, 1990, and 2000 and American Community Surveys for 2009-2011. Values for intervening years were based on linear interpolation.

The 3,143 US county equivalents were arranged into 2,356 merged county clusters, each consisting of a single county or multiple counties. The merging was done to account for changes in county boundaries over time to ensure consistency and to overcome the fact that some counties had very small numbers of deaths. National results were calculated directly from the raw data.

\section{Results}

For the US as a nation, female life expectancy increased from 78.0 years in 1985 to 80.9 years in 2010, and male life expectancy increased from 71.0 years in 1985 to 76.3 years in 2010. In 1985, the gap between female and male life expectancy was 7.0 years; this has narrowed progressively beginning in 2002 to only 4.6 years in 2010. The slower rates of improvement in female life expectancy, and consequently the narrowing gap, is consistent with the worsening national rank for female life expectancy across 187 countries (from 19 in 1985 to 39 in 2010), while the rank for males over this period changed from 29 to 40 [1].

Figure 1 shows trends in US life expectancy as well as the mean life expectancy across counties and the highest and lowest life expectancy in each year. For males in Figure 1, the highest life expectancy has steadily increased from 75.5 in 1985 to 81.7 in 2010, 0.25 years per calendar year. The lowest life expectancy remains below
65 throughout the entire 25-year period. For females, as seen in Figure 2, the highest life expectancy has increased 0.16 years per calendar year, from 81.1 to 85.0. The lowest life expectancy for females has remained relatively constant around 73 over the entire 25-year period. By 2010, the highest county-specific male life expectancy was greater than the female national life expectancy. The increasing difference in both Figures 1 and 2 between national life expectancy and the arithmetic mean of county-level life expectancy estimates indicates higher heterogeneity in life expectancy across counties. Moreover, it shows that an increasing number of counties have life expectancy at birth that are below the national values.

The expansion of disparities in county life expectancy throughout the period visible in Figures 1 and 2 is quantified using two metrics in Figures 3 and 4: the difference between the maximum and minimum life expectancy and the standard deviation of life expectancy across counties. These are computed separately for males and females. For males, there appears to have been three phases evident in both metrics of inequality: a period of rising inequality from 1985 to 1993, a period of stable inequality from 1993 to 2002, and rising inequality from 2002 to 2010. For females, in contrast, inequality has steadily increased during the 25 -year period. Of note, both metrics show that there is greater inequality in male life expectancy across counties than for females. As of 2010, female life expectancy at birth in Marin County, CA is 85.0 years (95\% uncertainty interval: 84.5, 85.6). In Perry County, KY, it is 72.7 years (71.3, $73.8)$, a gap of 12.3 years. For males, Fairfax County, VA had the highest life expectancy of 81.7 years $(81.3,82.0)$, while in McDowell County, WV it was 63.9 years $(62.0,65.6)$, a gap of 17.8 years. Even within a state there are wide disparities. For example, females in Loudon County, VA have the 12th-highest life expectancy at 84.2 years $(83.5,84.8)$, while in Petersburg County, VA females have the fifth-lowest at 73.7 years $(72.1,75.2)$.

Figures 5 and 6 show maps of US county life expectancy separately for males and females at four points: 1985, 1993, 2002, and 2010. These years correspond to apparent changes in the trends in disparities across US counties, especially for males. Some general patterns are evident. In all time periods, the lowest life expectancies are seen in the South, the Mississippi basin, West Virginia, Kentucky, and selected counties in the West and Midwest that have large Native American reservation populations. However, the maps reveal dramatic changes that have occurred unevenly across the US. Substantial improvements in life expectancy are seen in multiple locations: parts of California, most of Nevada, Colorado, rural Minnesota, Iowa, and parts of the Dakotas, some Northeastern states, and parts of Florida. 


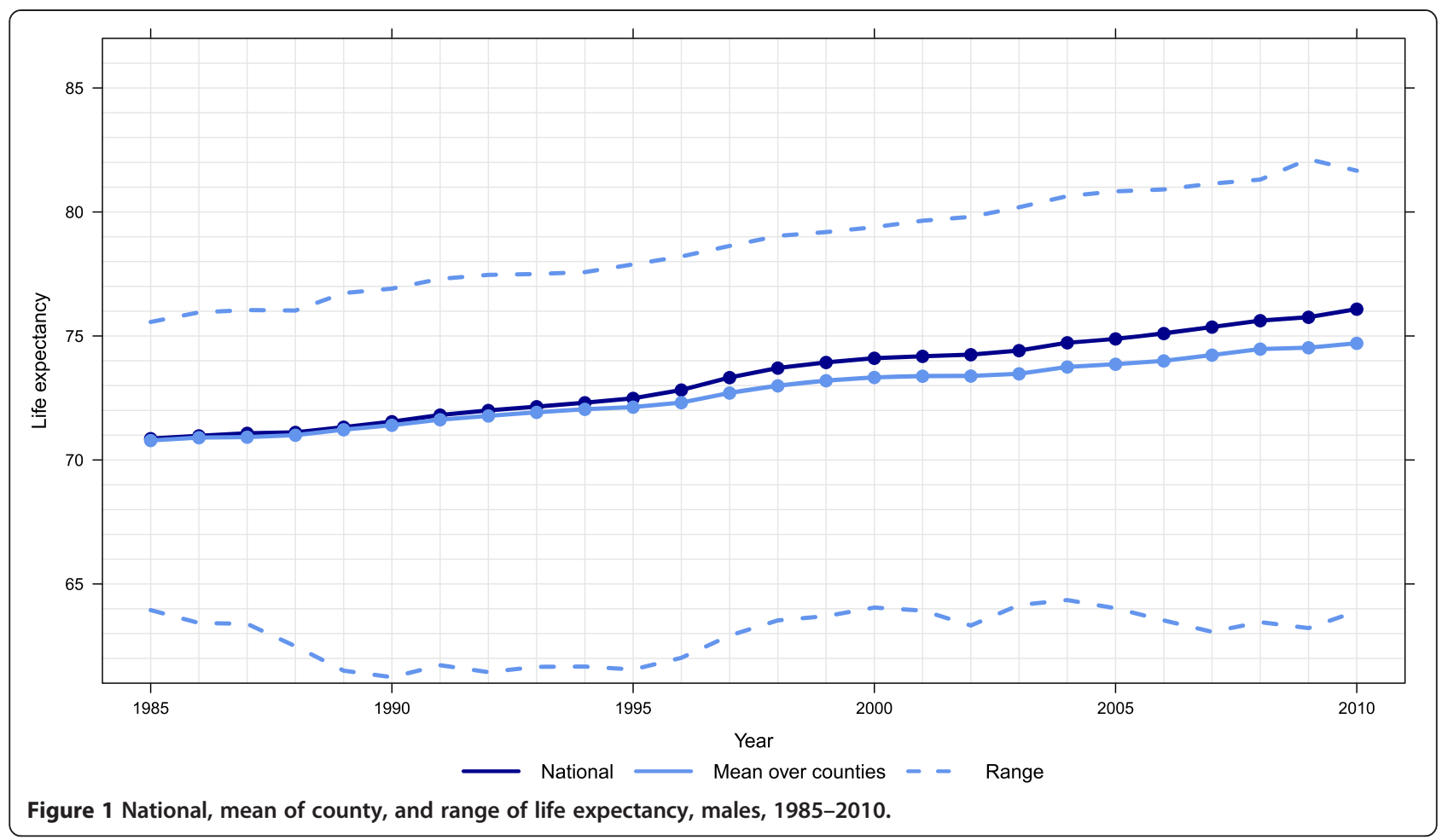

The improvements tend to occur in the same locations for males and for females. Table 1 lists the counties in the US with the highest and lowest life expectancies in 2010. Table 2 lists the counties with the largest increases and decreases between 1985 and 2010. The largest increases in life expectancy over the 25-year period for females were in four New York City counties, Marin and San Francisco counties in California, and in counties in Colorado, Wyoming, South Carolina, and New Jersey. For males, a number of counties in or near New York City along with multiple counties in

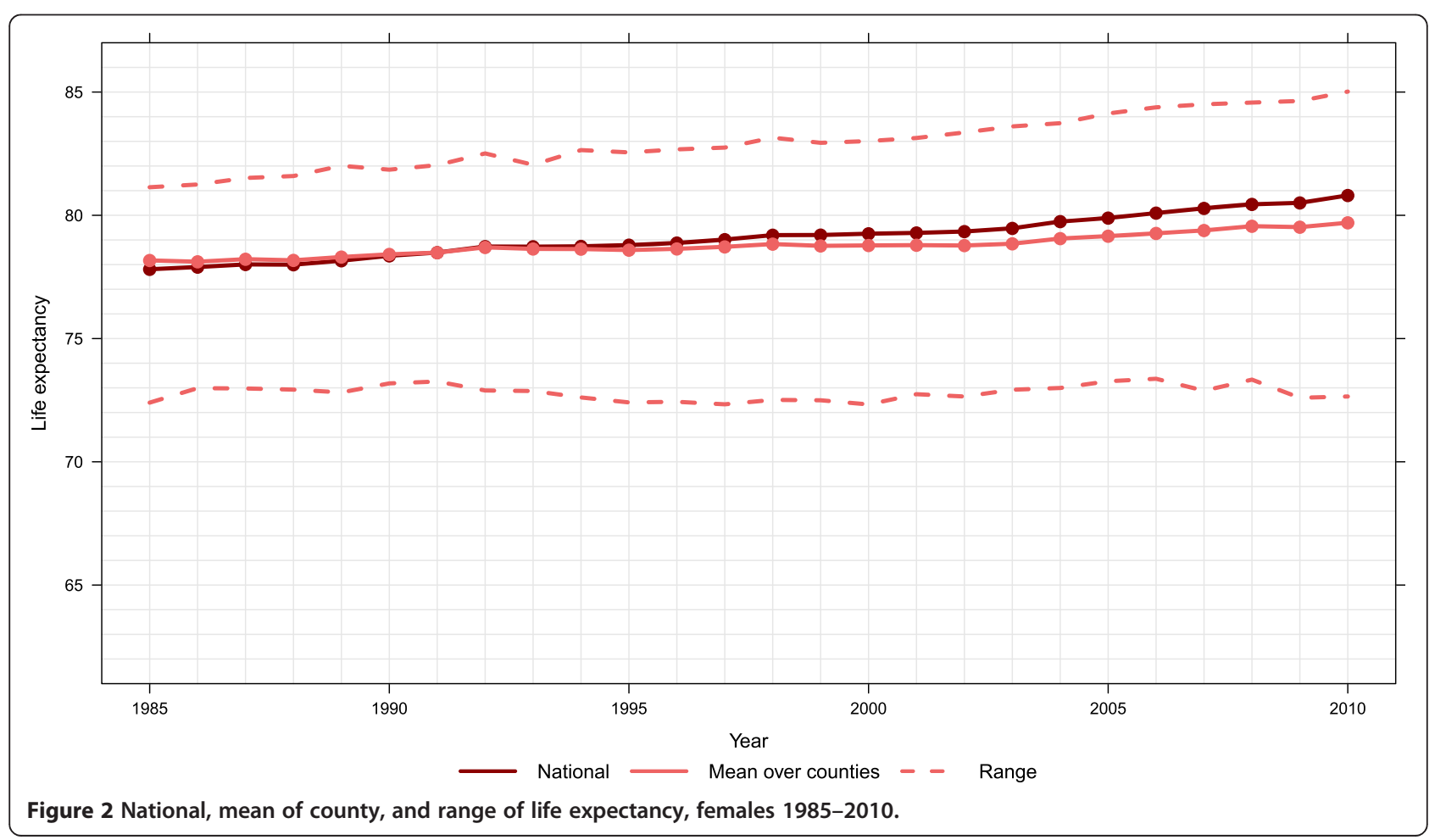




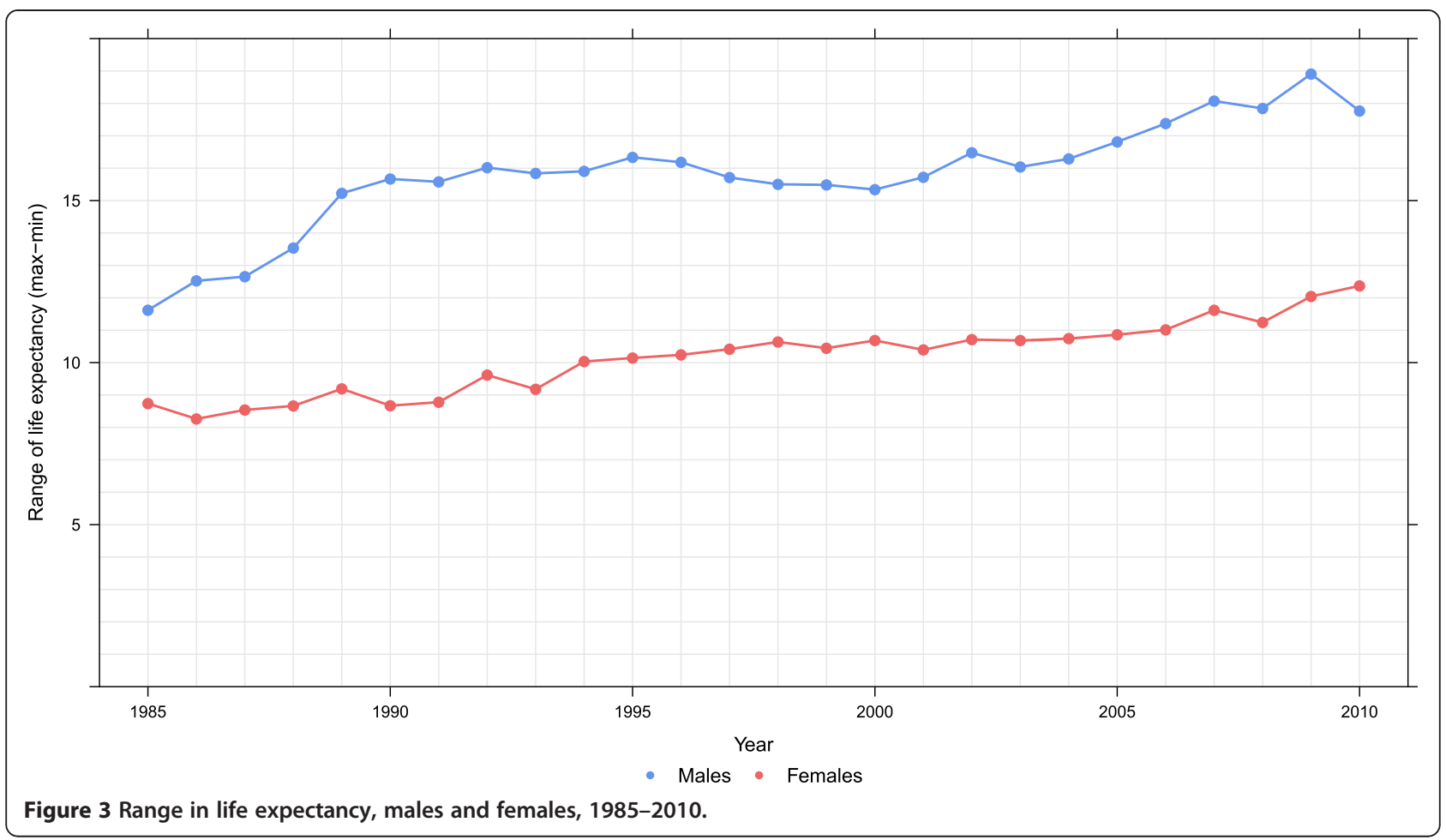

Virginia saw the largest gains. Ten of the worst-performing counties for females (with declines in life expectancy) were in Oklahoma, and five were in Kentucky. For males, the worst performers were in Kentucky, Oklahoma, Mississippi, and Alabama.
Over the three intervals, we have examined how many counties have observed statistically significant improvements in life expectancy, significant declines in life expectancy, or changes that were not statistically significant using a one-tailed test. Tables 3,4 and 5 show the cross-

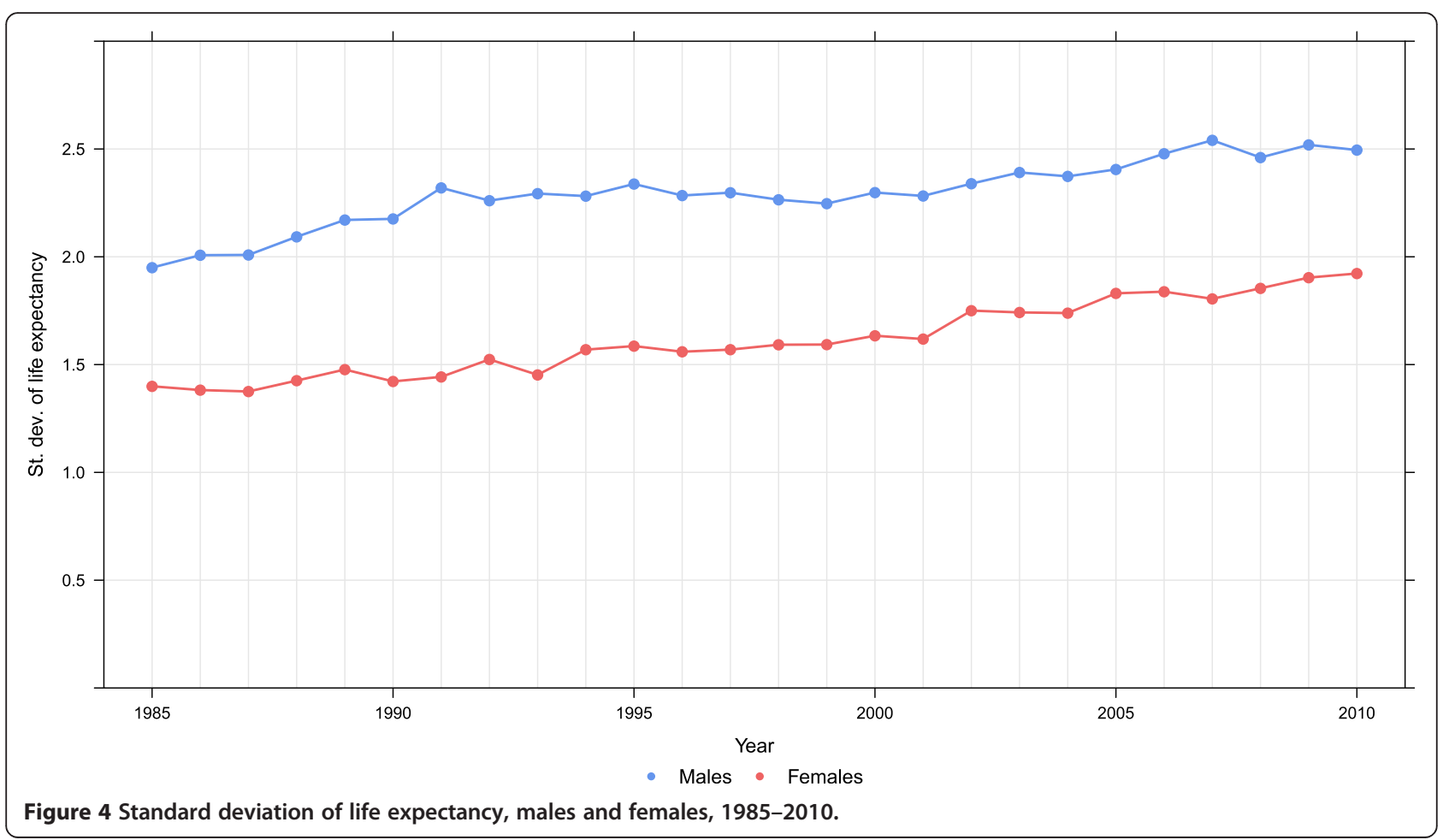




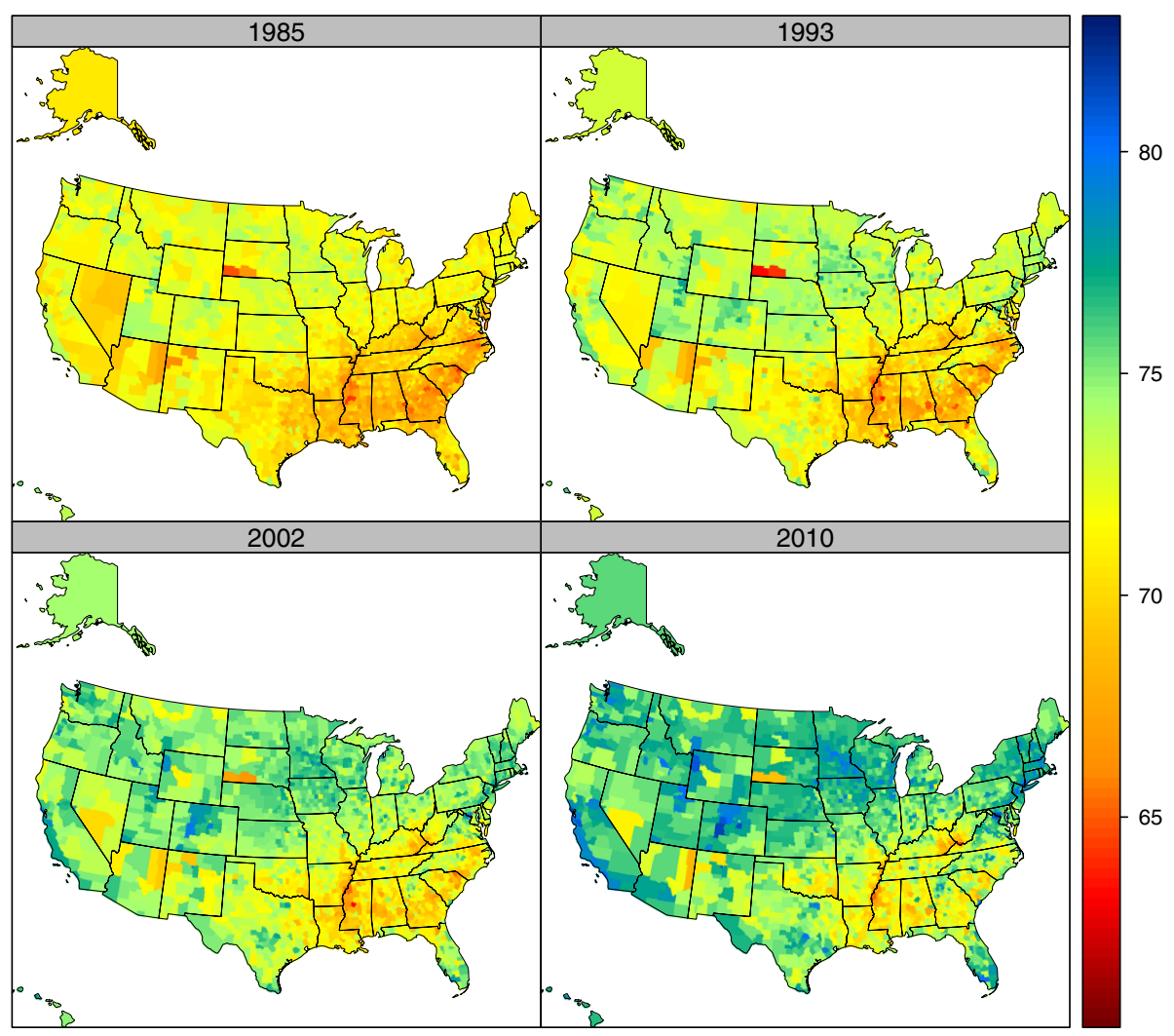

Figure 5 Life expectancy by county, males, 1985, 1993, 2002, and 2010.

tabulation of significant changes in male and female life expectancy for the three intervals. During the first interval, 42 counties saw declines for females and 32 for males. But nearly twice as many counties saw significant increases for males as for females; the vast majority of counties had no significant change for females. For the period from 1993 to 2002, male life expectancy declined significantly in only six counties, while it did so significantly in 300 for females. This marked difference is evident at the other end of the spectrum, where the number of counties with significant increases for males was 3.8 times higher than for females. This period of relatively good life expectancy outcomes for males in many counties has been followed by a period from 2002 to 2010 where outcomes for males and females have been more similar: 37 significant declines for females and nine for males, with 1,427 significant increases for females and 1,895 for males.

When we examine the changes in life expectancy at birth for the entire study period of 1985 to 2010, as shown in Figure 7, we observe significant decreases in life expectancy in only one county (Floyd County, KY) for males and 72 for females. The differences between males and females are more pronounced when we look at the counties with no significant change. For males, only 153 out of 3,143 counties have seen no significant change in life expectancy at birth. On the other hand, this number for females is 1,333 counties, or $42.4 \%$ of all counties in the US. Around $95.1 \%$ of the counties in the US have improved male life expectancy at birth from 1985 to 2010, while only just over half of all counties (55.3\%) have seen improved female life expectancy at birth during the same time period.

Figure 8 compares male and female life expectancy by county at the same four points in time as before: 1985, 1993, 2002, and 2010. The figure demonstrates the high correlation between female and male life expectancy by county at each point in time. It also shows how the gap between male and female life expectancy is as wide as 11 to 13 years for the counties with the lowest life expectancies and as narrow as two to four years for counties with the highest life expectancies. From 1993 to 2002, the slope of the relationship between female and male life expectancy became steeper as many more female counties had declines in life expectancy compared to males. The steadily rising life expectancy for males and females in the best-performing counties over time is also evident, as is the lack of progress at the other end of the distribution.

Figure 9 shows the locations of counties that have had significant declines for males, females, or both in the three time periods. During the period 1993-2002, the large number of counties with female declines but not 


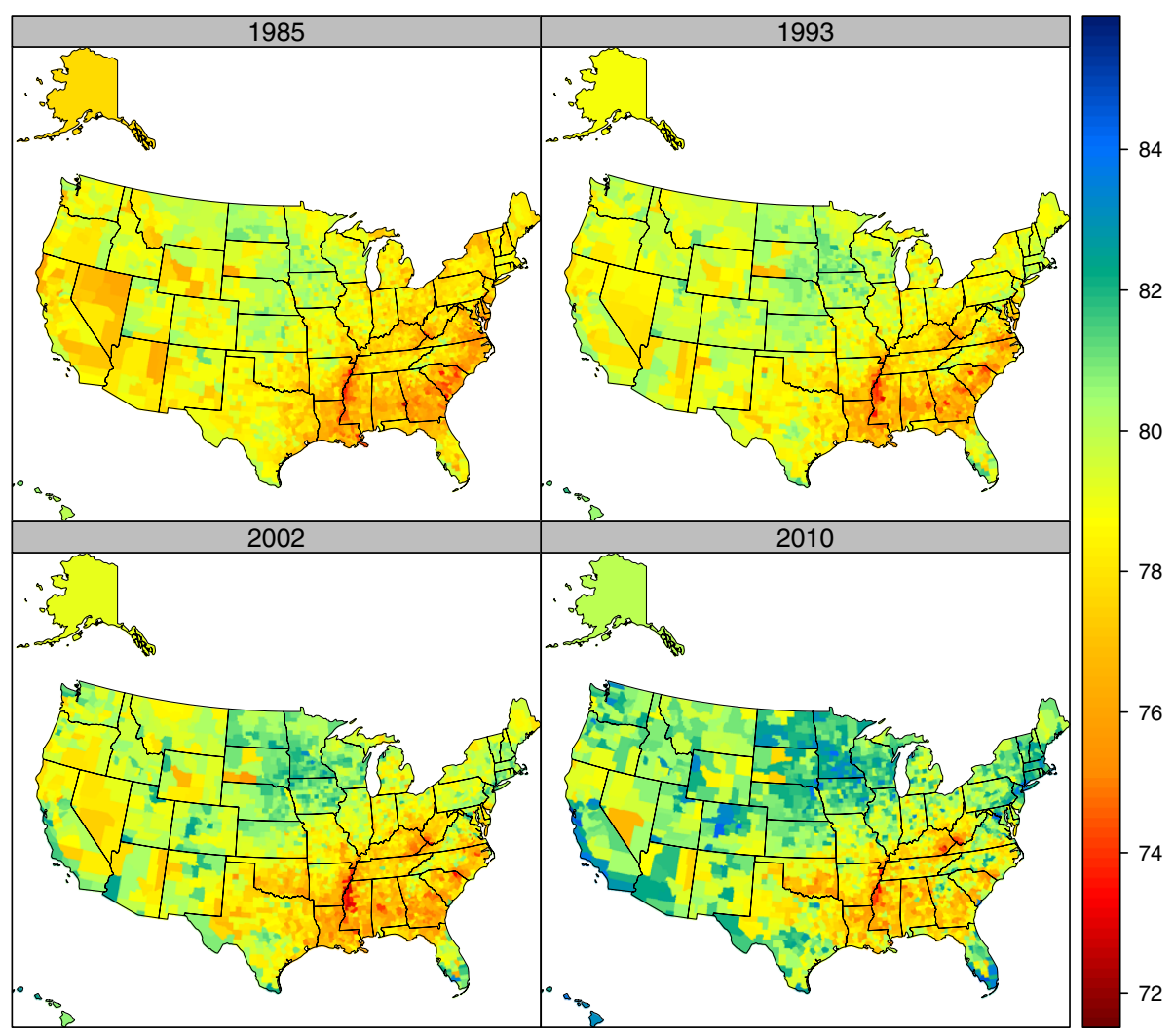

Figure 6 Life expectancy by county, females, 1985, 1993, 2002, and 2010.

male declines is evident in a belt from Texas to West Virginia. In addition, significant declines for females were seen in a few counties in Western states, some with Native American reservations. During the most recent period, the limited number of counties with declines in life expectancy was still in the same zone from Texas to West Virginia.

We have also included an additional file with male and female life expectancy in every county across all years of our study (Additional file 1).

\section{Discussion}

From 1985 to 2010, the US as a nation has seen improvements in life expectancy of $5.2(5.2,5.3)$ years for males and $3.0(2.9,3.0)$ years for females. However, these improvements are much less than what countries of similar income per capita have seen. Indeed, this slow pace of improvement has meant the global ranking of life expectancy in the US has fallen to 39 and 40 out of 187 nations for males and females, respectively. Faster growth in life expectancy for males than for females has narrowed the gender gap to 4.6 years in 2010. Examining these trends by county shows these national trends have occurred because of continued progress in expanding male and female life expectancy in a number of highperforming counties. The best counties have achieved female life expectancy of 85.0 and male life expectancy of 81.7 in 2010. At the same time, many counties have made no progress, or for the period 1993 to 2002, there have been declines for females in several hundred counties. Declines in life expectancy in some counties and stagnation in others means that inequality in life expectancy at birth among US counties increased dramatically from 1985 to 2010. In the last eight years, inequality in males has increased at an accelerated rate and remains consistently higher than for females despite the legacy of declining life expectancy from 1993 to 2002 for females in a substantial number of counties.

The reduction in the number of counties where female life expectancy is declining in the most recent period is welcome news. The decline in female life expectancy at birth in many counties from 1993 to 2002 needs explanation. Delayed peaks in female tobacco consumption compared to males may have been an important factor; for this period of time the impact of tobacco for males was declining and the impact for females was increasing. Lung cancer rates for females appear to have peaked around 2002 to 2005 at the national level [18-20]. Obesity is a major risk factor, with higher rates among females than males in many communities. Obesity levels increased in all counties but nine during the same time period [21]. Other studies have reported that the rates of 
Table 1 Top 20 and bottom 20 counties in terms of life expectancy by sex, 2010

\begin{tabular}{|c|c|c|c|c|c|c|c|c|c|}
\hline \multicolumn{6}{|c|}{ Top counties } & \multicolumn{4}{|c|}{ Bottom counties } \\
\hline $\begin{array}{l}\text { Rank } \\
\text { (top) }\end{array}$ & Name & Life expectancy & Lower & Upper & $\begin{array}{l}\text { Rank } \\
\text { (bottom) }\end{array}$ & Name & Life expectancy & Lower & Upper \\
\hline \multicolumn{10}{|c|}{ Females } \\
\hline 1 & Marin, California & 85.02 & 84.46 & 85.56 & 1 & Perry, Kentucky & 72.65 & 71.31 & 73.79 \\
\hline 2 & Montgomery, Maryland & 84.87 & 84.53 & 85.19 & 2 & McDowell, West Virginia & 72.90 & 71.37 & 74.29 \\
\hline 3 & Collier, Florida & 84.62 & 84.09 & 85.10 & 3 & Tunica, Mississippi & 73.36 & 71.69 & 74.63 \\
\hline 4 & Santa Clara, California & 84.54 & 84.29 & 84.80 & 4 & Quitman, Mississippi & 73.36 & 71.69 & 74.63 \\
\hline 5 & Fairfax County, Virginia & 84.52 & 84.19 & 84.84 & 5 & Petersburg, Virginia & 73.69 & 72.11 & 75.19 \\
\hline 6 & San Francisco, California & 84.38 & 84.02 & 84.73 & 6 & Sunflower, Mississippi & 73.85 & 72.26 & 75.16 \\
\hline 7 & Gunnison, Colorado & 84.33 & 83.04 & 85.47 & 7 & Mississippi, Arkansas & 73.85 & 72.70 & 74.95 \\
\hline 8 & Pitkin, Colorado & 84.33 & 83.04 & 85.47 & 8 & Mingo, West Virginia & 73.92 & 72.79 & 74.95 \\
\hline 9 & San Mateo, California & 84.30 & 83.94 & 84.70 & 9 & Washington, Mississippi & 74.09 & 72.93 & 75.19 \\
\hline 10 & Bergen, New Jersey & 84.26 & 83.95 & 84.56 & 10 & Leslie, Kentucky & 74.12 & 72.96 & 75.16 \\
\hline 11 & Douglas, Colorado & 84.17 & 83.56 & 84.77 & 11 & Clay, Kentucky & 74.12 & 72.96 & 75.16 \\
\hline 12 & Loudoun, Virginia & 84.16 & 83.54 & 84.77 & 12 & Bolivar, Mississippi & 74.32 & 73.08 & 75.45 \\
\hline 14 & Stearns, Minnesota & 84.13 & 83.42 & 84.82 & 13 & Phillips, Arkansas & 74.44 & 72.91 & 75.71 \\
\hline 13 & Lincoln, South Dakota & 84.11 & 82.94 & 85.24 & 14 & Logan, West Virginia & 74.50 & 73.35 & 75.66 \\
\hline 15 & New York, New York & 84.09 & 83.83 & 84.35 & 15 & Coahoma, Mississippi & 74.56 & 73.09 & 75.80 \\
\hline 16 & Westchester, New York & 84.05 & 83.75 & 84.36 & 16 & Holmes, Mississippi & 74.59 & 73.06 & 75.93 \\
\hline 17 & Brown, Minnesota & 83.86 & 82.66 & 84.87 & 17 & Wyoming, West Virginia & 74.79 & 73.47 & 75.97 \\
\hline 18 & Los Alamos, New Mexico & 83.86 & 82.62 & 85.05 & 18 & Harlan, Kentucky & 74.86 & 73.62 & 75.89 \\
\hline 19 & Orange, California & 83.82 & 83.62 & 84.02 & 19 & Haralson, Georgia & 74.89 & 73.69 & 75.99 \\
\hline 20 & Cedar, Nebraska & 83.81 & 82.48 & 85.01 & 20 & Franklin, Alabama & 74.92 & 73.80 & 75.91 \\
\hline \multicolumn{10}{|l|}{ Males } \\
\hline 1 & Fairfax County, Virginia & 81.67 & 81.32 & 82.02 & 1 & McDowell, West Virginia & 63.90 & 62.04 & 65.61 \\
\hline 2 & Gunnison, Colorado & 81.65 & 80.39 & 82.84 & 2 & Bolivar, Mississippi & 65.03 & 63.52 & 66.46 \\
\hline 3 & Pitkin, Colorado & 81.65 & 80.39 & 82.84 & 3 & Perry, Kentucky & 66.52 & 65.15 & 67.73 \\
\hline 4 & Montgomery, Maryland & 81.57 & 81.23 & 81.91 & 4 & Floyd, Kentucky & 66.59 & 65.22 & 67.86 \\
\hline 5 & Marin, California & 81.44 & 80.91 & 82.01 & 5 & Tunica, Mississippi & 66.70 & 65.18 & 68.04 \\
\hline 6 & Douglas, Colorado & 81.41 & 80.77 & 82.01 & 6 & Quitman, Mississippi & 66.70 & 65.18 & 68.04 \\
\hline 7 & Eagle, Colorado & 81.01 & 79.83 & 82.18 & 7 & Sunflower, Mississippi & 66.92 & 65.57 & 68.33 \\
\hline 8 & Loudoun, Virginia & 81.00 & 80.37 & 81.65 & 8 & Coahoma, Mississippi & 66.92 & 65.32 & 68.49 \\
\hline 9 & Santa Clara, California & 80.98 & 80.69 & 81.25 & 9 & Washington, Mississippi & 67.10 & 65.75 & 68.50 \\
\hline 10 & Teton, Wyoming & 80.93 & 79.85 & 81.84 & 10 & Macon, Alabama & 67.19 & 65.71 & 68.55 \\
\hline 11 & Los Alamos, New Mexico & 80.82 & 79.51 & 81.95 & 11 & Bullock, Alabama & 67.19 & 65.71 & 68.55 \\
\hline 12 & Bergen, New Jersey & 80.53 & 80.22 & 80.86 & 12 & Mingo, West Virginia & 67.26 & 65.91 & 68.57 \\
\hline 13 & Howard, Maryland & 80.41 & 79.79 & 80.98 & 13 & Phillips, Arkansas & 67.36 & 65.78 & 68.81 \\
\hline 14 & Leelanau, Michigan & 80.41 & 79.22 & 81.41 & 14 & Wyoming, West Virginia & 67.47 & 66.03 & 68.76 \\
\hline 15 & Arlington, Virginia & 80.39 & 79.76 & 81.11 & 15 & Owsley, Kentucky & 67.50 & 66.01 & 68.86 \\
\hline 16 & Falls Church, Virginia & 80.39 & 79.76 & 81.11 & 16 & Breathitt, Kentucky & 67.50 & 66.01 & 68.86 \\
\hline 17 & San Mateo, California & 80.34 & 79.98 & 80.71 & 17 & Pike, Kentucky & 67.50 & 66.36 & 68.57 \\
\hline 18 & Somerset, New Jersey & 80.18 & 79.70 & 80.66 & 18 & Petersburg, Virginia & 67.79 & 66.24 & 69.17 \\
\hline 19 & Summit, Colorado & 80.09 & 79.19 & 80.82 & 19 & Holmes, Mississippi & 67.87 & 66.19 & 69.45 \\
\hline 20 & Collier, Florida & 80.08 & 79.51 & 80.65 & 20 & Sharkey, Mississippi & 67.95 & 65.85 & 69.67 \\
\hline
\end{tabular}


Table 2 Top 20 and bottom 20 counties in terms of change in life expectancy by sex, 1985-2010

\begin{tabular}{|c|c|c|c|c|c|c|c|c|c|}
\hline \multicolumn{5}{|c|}{ Top counties } & \multicolumn{5}{|c|}{ Bottom counties } \\
\hline Rank (top) & Name & $\begin{array}{l}\text { Change in life } \\
\text { expectancy }\end{array}$ & Lower & Upper & $\begin{array}{l}\text { Rank } \\
\text { (bottom) }\end{array}$ & Name & $\begin{array}{l}\text { Change in life } \\
\text { expectancy }\end{array}$ & Lower & Upper \\
\hline \multicolumn{10}{|l|}{ Females } \\
\hline 1 & New York, New York & 8.37 & 7.91 & 8.79 & 1 & Fayette, Alabama & -3.47 & -5.41 & -1.71 \\
\hline 2 & Loudoun, Virginia & 7.77 & 6.59 & 8.99 & 2 & Harmon, Oklahoma & -3.39 & -5.07 & -1.6 \\
\hline 3 & Kings, New York & 6.7 & 6.37 & 7.03 & 3 & Beckham, Oklahoma & -3.39 & -5.07 & -1.6 \\
\hline 4 & Bronx, New York & 6.39 & 5.91 & 6.85 & 4 & Leslie, Kentucky & -3.17 & -4.75 & -1.59 \\
\hline 5 & Gunnison, Colorado & 6.28 & 4.58 & 7.91 & 5 & Clay, Kentucky & -3.17 & -4.75 & -1.59 \\
\hline 6 & Pitkin, Colorado & 6.28 & 4.58 & 7.91 & 6 & Seminole, Oklahoma & -2.73 & -4.35 & -1.13 \\
\hline 7 & Marin, California & 6.27 & 5.47 & 7.07 & 7 & Haralson, Georgia & -2.58 & -4.46 & -0.89 \\
\hline 8 & Prince William, Virginia & 6.09 & 5.02 & 7.13 & 8 & Murray, Oklahoma & -2.58 & -4.06 & -1.17 \\
\hline 9 & San Francisco, California & 6.05 & 5.52 & 6.61 & 9 & Garvin, Oklahoma & -2.58 & -4.06 & -1.17 \\
\hline 10 & Beaufort, South Carolina & 6.02 & 4.78 & 7.28 & 10 & Perry, Kentucky & -2.57 & -4.34 & -0.92 \\
\hline 11 & Queens, New York & 6.01 & 5.69 & 6.35 & 11 & Johnston, Oklahoma & -2.52 & -4.38 & -0.78 \\
\hline 12 & St. Johns, Florida & 5.94 & 4.87 & 7.14 & 12 & Coal, Oklahoma & -2.52 & -4.38 & -0.78 \\
\hline 14 & Teton, Wyoming & 5.8 & 3.82 & 7.72 & 13 & Pontotoc, Oklahoma & -2.5 & -4.26 & -0.8 \\
\hline 13 & Douglas, Colorado & 5.75 & 4.3 & 7.29 & 14 & Tillman, Oklahoma & -2.43 & -3.98 & -0.82 \\
\hline 15 & Hudson, New Jersey & 5.73 & 5.11 & 6.29 & 15 & Jefferson, Oklahoma & -2.43 & -3.98 & -0.82 \\
\hline 16 & Rockland, New York & 5.72 & 5.01 & 6.52 & 16 & Cotton, Oklahoma & -2.43 & -3.98 & -0.82 \\
\hline 17 & Alexandria, Virginia & 5.59 & 4.4 & 6.84 & 17 & Walker, Alabama & -2.34 & -3.81 & -1.03 \\
\hline 18 & Nassau, New York & 5.51 & 5.11 & 5.89 & 18 & Whitley, Kentucky & -2.3 & -3.89 & -0.72 \\
\hline 19 & Pike, Pennsylvania & 5.5 & 5.07 & 5.93 & 19 & Casey, Kentucky & -2.29 & -4.11 & -0.72 \\
\hline 20 & Alameda, California & 5.5 & 3.88 & 6.98 & 20 & Marion, Alabama & -2.27 & -3.75 & -0.73 \\
\hline \multicolumn{10}{|l|}{ Males } \\
\hline 1 & New York, New York & 12.97 & 12.55 & 13.41 & 1 & Floyd, Kentucky & -1.49 & -3.23 & 0.3 \\
\hline 2 & San Francisco, California & 10.6 & 10.05 & 11.18 & 2 & McDowell, West Virginia & -1.45 & -3.62 & 0.75 \\
\hline 3 & Kings, New York & 9.76 & 9.39 & 10.12 & 3 & Bolivar, Mississippi & -0.98 & -2.91 & 1.1 \\
\hline 4 & Loudoun, Virginia & 9.59 & 8.51 & 10.75 & 4 & Perry, Alabama & -0.87 & -2.76 & 1.27 \\
\hline 5 & Bronx, New York & 9.57 & 9.08 & 10.1 & 5 & Hale, Alabama & -0.87 & -2.76 & 1.27 \\
\hline 6 & District of Columbia & 9.37 & 8.67 & 10.09 & 6 & Creek, Oklahoma & -0.69 & -2.1 & 0.74 \\
\hline 7 & Forsyth, Georgia & 9.16 & 7.71 & 10.74 & 7 & Wyoming, West Virginia & -0.65 & -2.44 & 1.27 \\
\hline 8 & Goochland, Virginia & 9.15 & 7.51 & 10.89 & 8 & Cherokee, Kansas & -0.56 & -2.3 & 1.19 \\
\hline 9 & Alexandria, Virginia & 8.84 & 7.48 & 10.13 & 9 & Grundy, Tennessee & -0.55 & -2.88 & 1.5 \\
\hline 10 & Hudson, New Jersey & 8.63 & 8.06 & 9.23 & 10 & Danville, Virginia & -0.36 & -1.99 & 1.34 \\
\hline 11 & Queens, New York & 8.5 & 8.12 & 8.88 & 11 & Aransas, Texas & -0.34 & -2.15 & 1.44 \\
\hline 12 & Colusa, California & 8.45 & 6.54 & 10.5 & 12 & Pike, Kentucky & -0.31 & -1.81 & 1.09 \\
\hline 13 & Suffolk, Virginia & 8.34 & 6.86 & 9.87 & 13 & Owsley, Kentucky & -0.23 & -2.09 & 1.79 \\
\hline 14 & Collier, Florida & 8.19 & 7.19 & 9.26 & 14 & Breathitt, Kentucky & -0.23 & -2.09 & 1.79 \\
\hline 15 & Sumter, Florida & 8.13 & 6.73 & 9.69 & 15 & Benton, Tennessee & -0.19 & -2.3 & 2.04 \\
\hline 16 & Rockwall, Texas & 8.08 & 6.56 & 9.77 & 16 & Mingo, West Virginia & -0.09 & -1.88 & 1.67 \\
\hline 17 & Gunnison, Colorado & 8.02 & 6.22 & 9.92 & 17 & Wolfe, Kentucky & 0.01 & -1.87 & 2.02 \\
\hline 18 & Pitkin, Colorado & 8.02 & 6.22 & 9.92 & 18 & Lee, Kentucky & 0.01 & -1.87 & 2.02 \\
\hline 19 & Alameda, California & 8.01 & 7.56 & 8.45 & 19 & Pawnee, Oklahoma & 0.04 & -1.8 & 1.94 \\
\hline 20 & Dawson, Georgia & 8 & 6.18 & 9.83 & 20 & Coahoma, Mississippi & 0.06 & -2.01 & 2.15 \\
\hline
\end{tabular}


Table 3 Number of counties with significant changes in males vs. females, 1985-1993

\begin{tabular}{lrrrr}
\hline & \multicolumn{3}{c}{ Males } \\
\cline { 2 - 4 } Females & Significant increase & No significant change & Significant decrease & Total \\
\hline Significant Increase & 632 & 147 & 7 \\
No Significant Change & 880 & 1411 & 24 \\
Significant Decrease & 3 & 38 & 2315 \\
Total & 1515 & 1596 & 42 \\
\hline
\end{tabular}

increase in obesity at the national level may have also been slowing in the most recent time period [22,23]. Declines in female life expectancy were concentrated in the central part of the US, particularly in a belt from Texas to West Virginia; more detailed analyses would be helpful in understanding the concentration in these areas.

During the period covered by this study, life expectancy at birth among Organization for Economic Cooperation and Development (OECD) countries increased 4.45 years for males and 5.75 years for females [1]. Yet our study shows large segments of the US had no significant increases in life expectancy for females. In contrast, some counties in the US saw increases far above the OECD average. Understanding why there has been no progress for females in so many counties is an important priority requiring further research.

In addition, the stagnation in life expectancy in a substantial number of counties alongside improvements in life expectancy in many others has led to steadily widening inequalities. Despite the period of falling life expectancy for females in many counties, inequalities for males are larger than for females. The gap in life expectancy at birth between males and females steadily narrows as pace of improvement in male life expectancy has been much faster than that of females. This suggests that if the trends continue, differences between male and female life expectancy will eventually be much smaller than we currently observe. Indeed, these findings raise some serious questions to our public health systems. What are the causes for the steady increase in inequalities? Why are parts of America being left behind while some others are enjoying increasing gains in life expectancy?

To present our findings in perspective to changes occurring on the global level, we compared the life expectancy in the US counties in 2010 to those of other countries as calculated in the Global Burden of Diseases, Injuries, and Risk Factors Study 2010 [1]. The top counties for females, such as Marin County, CA and Montgomery County, MD, have life expectancies that rival some countries where people live the longest, such as Switzerland, Spain, and France. Montgomery, MD has a female life expectancy at birth that is slightly higher than Japan. For males, the top counties, such as Fairfax County, VA and Gunnison County, CO, have life expectancies higher than the top countries, such as Switzerland and Japan. Life expectancy for males in $11 \%$ and for females in $14 \%$ of US counties was below that of Nicaragua. In some counties, such as McDowell County, WV and Sunflower County, MS, life expectancies are lower than Bangladesh for males and Algeria for females. The complete failure by some communities to increase life expectancy from levels seen now in very poor countries likely has many distal and proximate causes. But most importantly, this slow progress should be viewed as a call for action to improve health and reduce inequalities in the US.

Stagnant or even declining life expectancies in some communities could be related to five types of factors: 1 ) migration; 2) socioeconomic factors such as poverty and education; 3) lack of access to health care; 4) poor quality of health care for those with access; and 5) behavioral, environmental, and metabolic risk factors. All could be operating simultaneously to explain some of the patterns observed at the county level. One explanation for the widening disparities could be that healthier individuals are migrating from disadvantaged communities, which could lower life expectancy in the community they left and raise it in the community they move to. Ezzati et al. [8] used Internal Revenue Service tax records that record movements from county to county to explore how much migration might explain disparities.

Table 4 Number of counties with significant changes in males vs. females, 1993-2002

\begin{tabular}{lrrrr}
\hline & \multicolumn{3}{c}{ Males } & \\
\cline { 2 - 5 } Females & Significant Increase & No Significant Change & Significant Decrease & 0 \\
\hline Significant Increase & 573 & 33 & 606 \\
No Significant Change & 1612 & 624 & 1 \\
Significant Decrease & 143 & 152 & 2237 \\
Total & 2328 & 809 & 300 \\
\hline
\end{tabular}


Table 5 Number of counties with significant changes males vs. females, 2002-2010

\begin{tabular}{lrrrr}
\hline & \multicolumn{3}{c}{ Males } & Significant decrease \\
\cline { 2 - 4 } Females & Significant increase & No significant change & 0 & Total \\
\hline Significant Increase & 1095 & 332 & 1427 \\
No Significant Change & 788 & 884 & 7 & 1679 \\
Significant Decrease & 12 & 23 & 37 \\
Total & 1895 & 1239 & 3143 \\
\hline
\end{tabular}

They found that in general individuals moved from high life expectancy to low life expectancy communities and not the reverse. While their finding suggests migration may not be a major factor in the national patterns, it could be an important factor in selected counties that have experienced substantial in- or out-migration. On the other hand, net immigration of young Hispanic adults with lower mortality could have tended to increase life expectancy at birth for some counties and the nation as a whole.

Many studies have showed that socioeconomic factors are associated with poor health outcomes $[24,25]$. The patterns we report, however, cannot be simply explained by county-level changes in income per capita. During the period 1993 to 2002, US economic growth was associated with worsening inequality especially for women. Simple comparisons of change in life expectancy and change in income per capita at the county level for the period 1985 to 2010 show effectively no relationship. Mother's education has a strong protective effect on child mortality [26-30]. Females with higher education are more likely to know the danger signs for their health and that of their families. They may be more likely to seek medical care and adhere to it. The Institute of Medicine report on shorter lives [31] has emphasized the importance of social factors including poverty and inequality rates in understanding poor overall outcomes in the US. Simple comparisons of change in county life expectancy and change in educational attainment in this analysis do not show the expected relationship. While income, education, and economic inequality are likely important factors, they are not the only determinants of outcomes; the consistently high life expectancies seen in rural and below-median-income counties in Minnesota, Iowa, and parts of the Dakotas indicate that there are more complex factors that may also be important.

In the US, many individuals lack health insurance or are underinsured, and lack of health insurance has been shown at the individual level to be associated with increased risk of poor health outcomes [32]. At the community level, however, it has been more difficult to show a relationship between insurance coverage and mortality

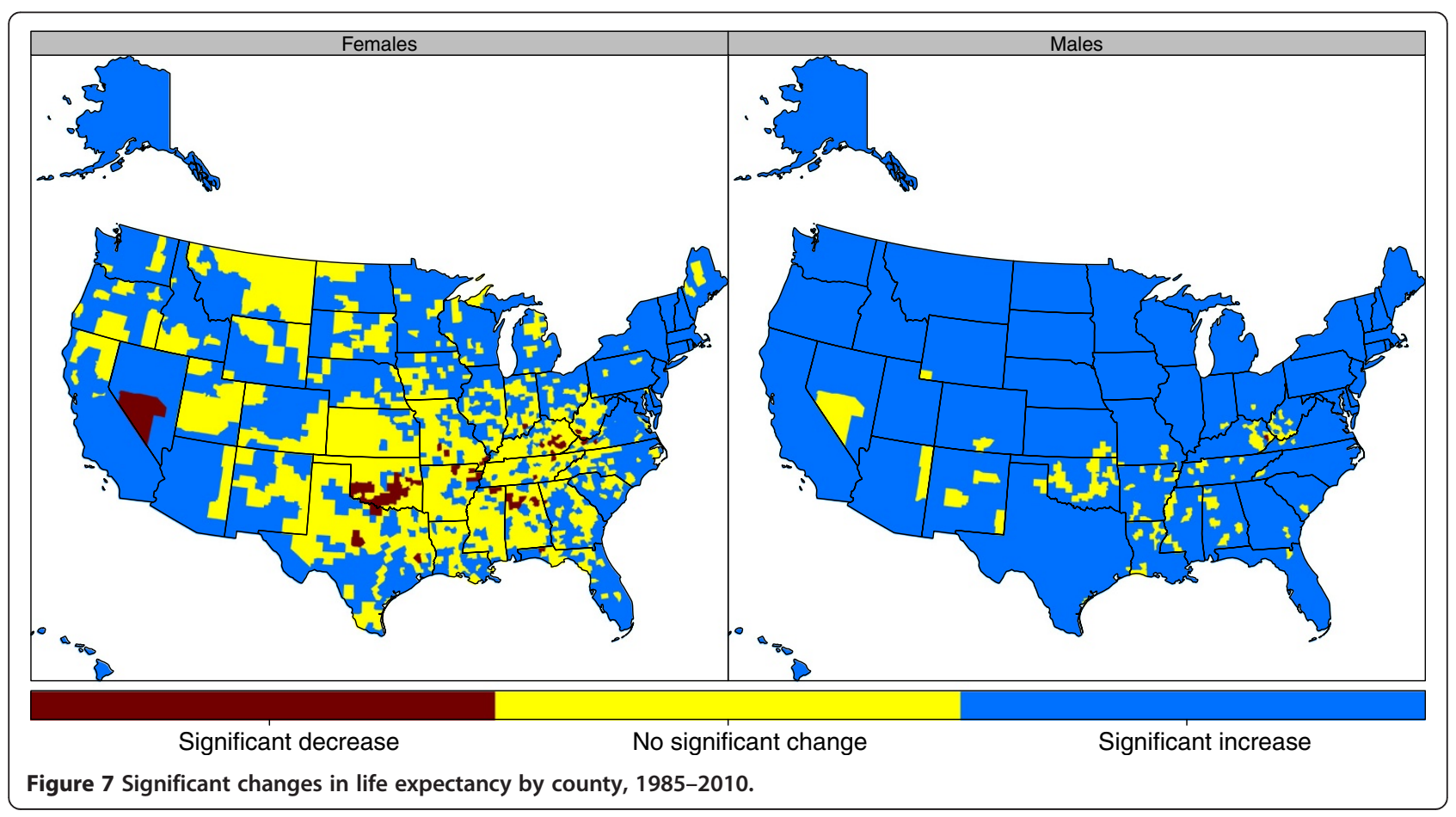




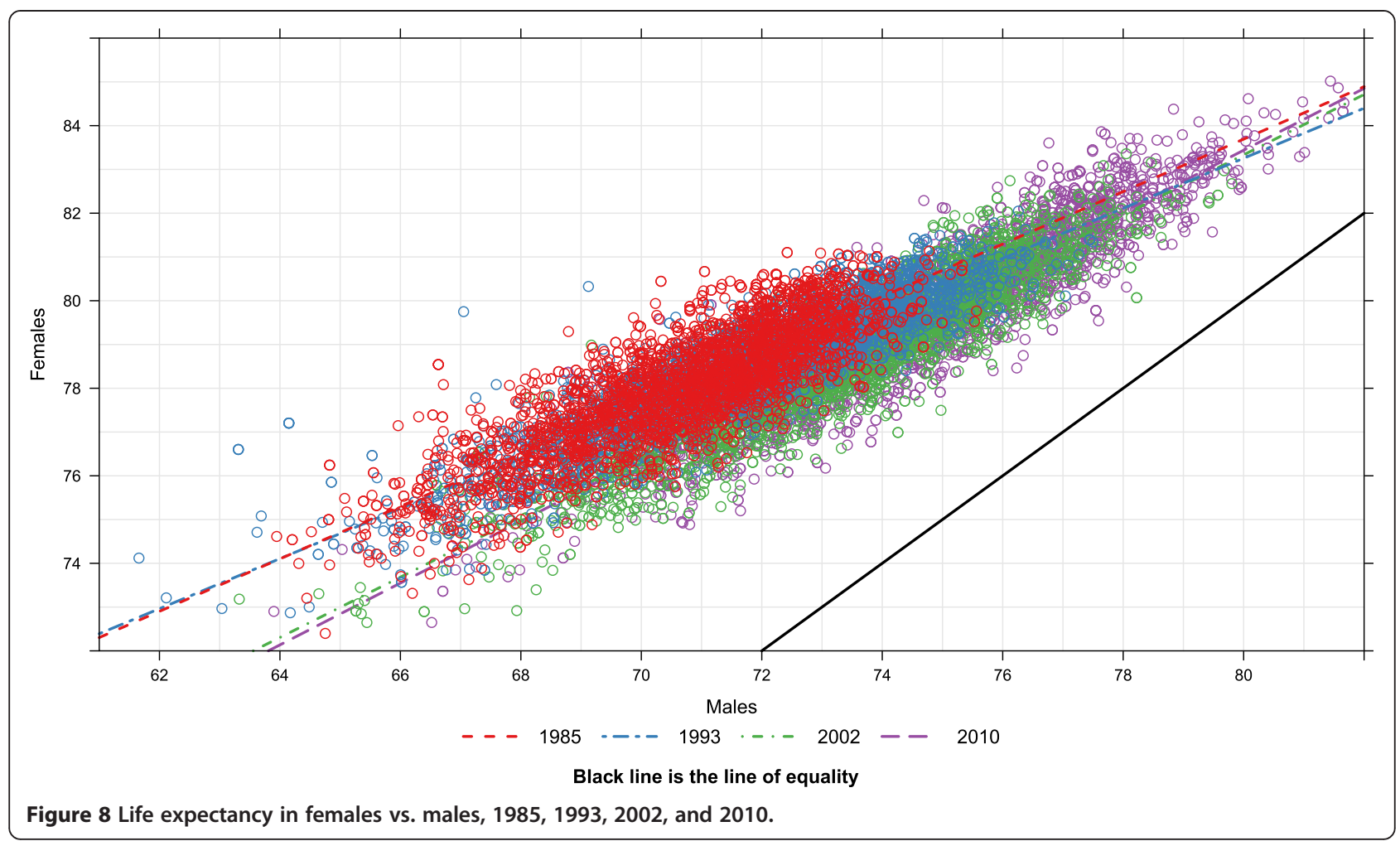

outcomes [33]. Simple correlation analysis at the county level, however, does not show a relationship to life expectancy. The disconnect between the clear findings on insurance and individual outcomes and the lack of this association at the community level suggests other factors intervene that are more powerful determinants of poor outcomes at the community level. The quality of medical care is another determinant of health outcome [34]. However, this does not involve only medical errors. Good medical care ensures that patients are properly followed to receive treatment and that conditions are controlled. Appropriate management of key conditions such as elevated blood pressure varies substantially across counties [35].

Modifiable behavioral, environmental, and metabolic risk factors are critical determinants of health in the US and likely critical determinants of health at the community level. Levels of obesity, for example, are highly correlated with mortality and life expectancy $[21,36]$. Previous studies reported on the association between

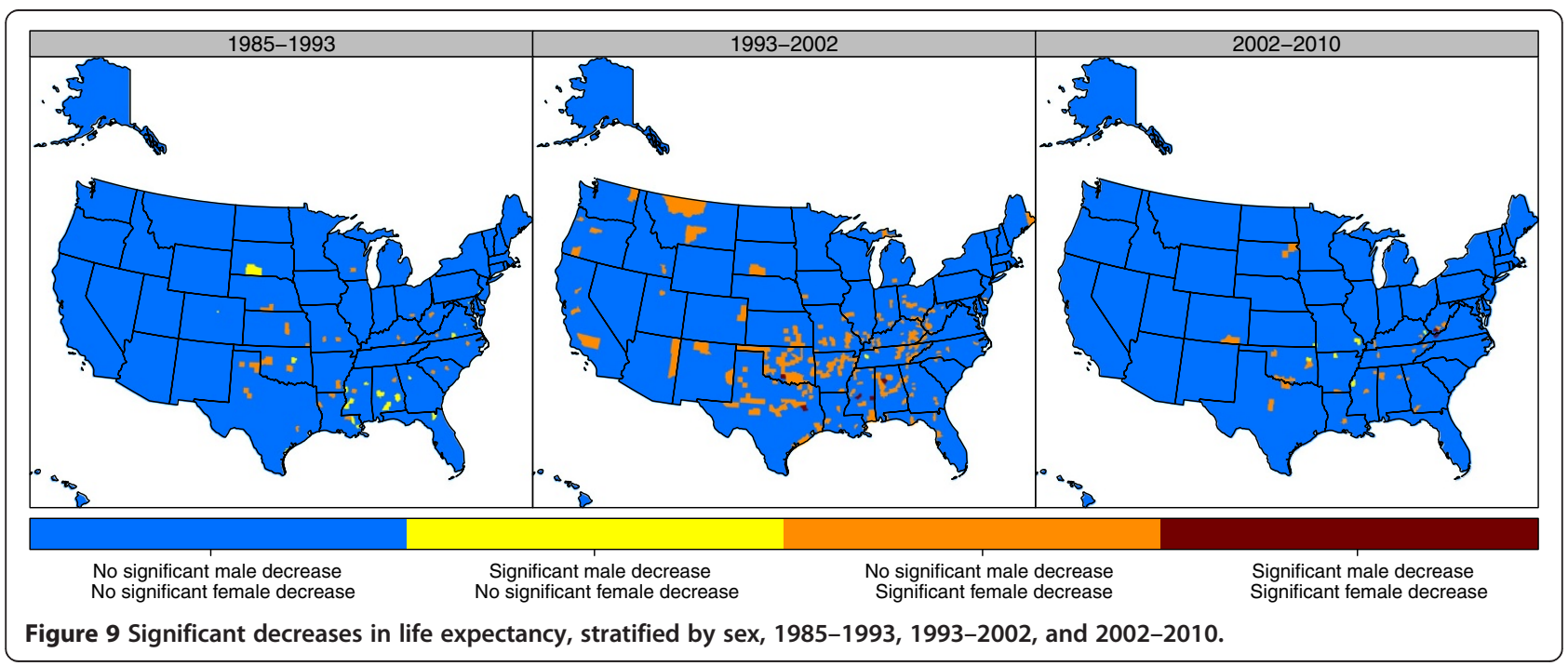


preventable risk factors and premature mortality [36,37]. Poor diet, physical inactivity, and smoking accounted for $51.8 \%$ of premature deaths in the US in $2010[9,36]$. Therefore, the biggest efforts should be to reduce these risk factors across the US. Unfortunately, data on the prevalence and changes of these risk factors at the county level are lacking.

Given the diversity of demography, epidemiology, physical infrastructure, and health system organization at the local level, a single national solution may not be the most effective for all risk factors. Different approaches should be implemented and evaluated. Indeed, prevention should be viewed as an investment, like retirement funds, where diversifying the portfolio is a key for success. A county health department or the federal government could then shift resources to interventions that are successful and stop funding what is not working.

Several studies have reported that medical practitioners have a key role in prevention $[38,39]$. Patients who received medical advice to reduce weight or stop smoking were more likely to attempt and achieve these behavior changes. Therefore, involving the medical system in prevention across the US is crucial. Hospitals and medical centers should be encouraged to be involved in prevention efforts in their community. The possible benefits (and costs) of introducing a system for grading and reimbursing health facilities based in part on the level of health improvements in the population they serve may be worth exploring. Several countries have successfully involved their medical facilities in preventive efforts [40-46]. Research using appropriate time-series crosssectional methods and carefully constructed county-level covariates for all the potential key determinants is a priority for future work. It is only when this work is undertaken that a coherent assessment of the contributions of different distal and proximal factors will be available.

This study is largely descriptive, but because it uses a statistical model to estimate age-specific mortality at the county level, it has important limitations. In counties with small populations, life expectancy estimates are substantially informed by patterns in adjacent counties as well as levels of income, education, and racial composition. Our estimation procedure generates substantial uncertainty intervals. Underlying levels of mortality risk may in some small communities be substantially higher or lower than we estimate using our approach. Despite this important limitation, the use of mixed effects Poisson regression with spatial correlation of random effects combined with Gaussian Process Regression yields estimates with much narrower uncertainty intervals for small areas than uncertainty intervals generated using the binomial distribution and the normal approximation of binomial distribution of the observed data solely on the basis of sampling error. Alternative geospatial models have been proposed $[16,47]$. It will be important in future research to subject a range of alternative geospatial modeling strategies to rigorous out-of-sample predictive validity testing. It is also important to note that while life expectancy at birth is constructed to summarize period age-specific mortality rates, agespecific mortality rates in the youngest age groups and the changes therein have a much bigger impact on life expectancy at birth. To address this issue, we have examined the trends of standard deviation of the age-specific mortality rates in logarithmic scale. All age groups used in this study (18 out of the 18 five-year age groups) saw increases in the standard deviation of death rates in log scale. Therefore, increasing inequalities exist among all age groups.

Kindig and Cheng [16] recently reported that $42.8 \%$ of counties observed increases in female age-standardized death rates from the period of 1992-1996 to the period of 2002-2006. It is important to note that choice of standard population distribution could potentially alter the conclusion drawn from the comparison. We believe life expectancy, at birth or by age, is a more appropriate measurement in looking at the changes in mortality over time and across countries. When we use our life expectancy at birth generated in this study, we find many fewer counties have had statistically significant declines in life expectancy. Kindig and Cheng model directly the change in the age-standardized rate using fixed effects and state and county random effects. They report increases without indicating whether these changes are statistically significant or not. In applying the same methodology to the same time periods as Kindig and Cheng, we found that $30.4 \%$ of counties experienced an increase in agestandardized death rates for females, but the increase was significant in only $2.4 \%$. In addition, our methods are not the same, as we first estimate age-specific death rates and then compute full life tables with uncertainty. We have noted that the number of counties with significant declines in female life expectancy has attenuated since 2002. It is also important to note that we have a longer time period compared to Kindig and Cheng [16], Kulkarni et al. [11], and Murray et al. [9]. Indeed, our longer time period and the use of more updated population estimates in our denominators enabled us to produce a more robust conclusion on the changes in mortality and inequality over time.

For nearly two decades, studies have drawn attention to wide disparities in life expectancy at the county level. Despite some attention and policy discussion, disparities continue to increase. Simply put, as a nation, the United States has failed to make any progress in reducing disparities at the county level, even though national life expectancy has increased. Large numbers of communities 
are being left behind; they are not seeing any increase in life expectancy. New strategies are needed to address this growing problem. While further understanding of the social, economic, and cultural distal determinants of health may provide critical insights, we also believe that a focus on modifiable behavioral, environmental, and metabolic risk factors provides a strategy that could work in the shorter term as well.

\section{Additional file}

Additional file 1: Life expectancy for both sexes in every county across all years of the study (1985-2010).

\section{Competing interests}

All authors declare that they have no competing interests and therefore have nothing to declare with the exception of stating our core grant funding from the state of Washington.

\section{Authors' contributions}

CJLM, AES, and HW developed and applied the model to estimate mortality by age, sex, and race by county. AHM and CJLM designed the overall study and analytical strategy. AHM and CJLM wrote the first draft and revised the paper. All authors have read and approved the final manuscript.

\section{Acknowledgments}

This research was supported by funding from the state of Washington. The funders had no role in study design, data collection and analysis,

interpretation of data, decision to publish, or preparation of the manuscript. The corresponding author had full access to all data analyzed and had final responsibility for the decision to submit this original research paper for publication.

Received: 10 June 2013 Accepted: 1 July 2013

Published: 10 July 2013

\section{References}

1. Wang H, Dwyer-Lindgren L, Lofgren KT, Rajaratnam JK, Marcus JR, LevinRector A, Levitz CE, Lopez AD, Murray CJ: Age-specific and sex-specific mortality in 187 countries, 1970-2010: a systematic analysis for the global burden of disease study 2010. Lancet 2012, 380:2071-2094.

2. Dougherty DCP: The " $3 \mathrm{t}^{\prime} \mathrm{s}$ " road map to transform us health care: the "how" of High-quality care. JAMA 2008, 299:2319-2321.

3. Emanuel EJFV: The perfect storm of overutilization. JAMA 2008, 299:2789-2791.

4. Peterson CL, Rachel B: US Health Care Spending: Comparison with Other OECD Countries. Washington, DC: Congressional Research Service Federal Publications; 2007.

5. Fuchs VR: How and why US health care differs from that in other OECD countries. Jama J Am Med Assoc 2013, 309:33-34.

6. Woolf SH, Aron L (Eds): U.S. Health in International Perspective: Shorter Lives, Poorer Health. Washington, DC: The National Academies Press; 2013.

7. Ho JY: Mortality Under Age 50 accounts for Much of the fact That US life expectancy lags That of other High-income countries. Health Aff (Millwood) 2013, 32:459-467.

8. Ezzati M, Friedman AB, Kulkarni SC, Murray CJL: The reversal of fortunes: trends in county mortality and cross-county mortality disparities in the United states. Plos Med 2008, 5:e66.

9. Murray CJL, Kulkarni SC, Michaud C, Tomijima N, Bulzacchelli MT, landiorio TJ, Ezzati M: Eight Americas: investigating mortality disparities across races, counties, and race-counties in the United states. Plos Med 2006, 3:e260.

10. Cullen MR, Cummins C, Fuchs VR: Geographic and racial variation in premature mortality in the U.S.: analyzing the disparities. Plos One 2012, 7:e32930.
11. Kulkarni SC, Levin-Rector A, Ezzati M, Murray CJ: Falling behind: life expectancy in US counties from 2000 to 2007 in an international context. Popul Heal Metrics 2011, 9:16.

12. Koh HK, Graham G, Glied SA: Reducing racial and ethnic disparities: the action plan from the department of health and human services. Heal Aff Proj Hope 2011, 30:1822-1829.

13. Miech R, Pampel FC, Jinyoung K, Rogers RG: The enduring association between education and mortality: the role of widening and narrowing disparities. Am Sociol Rev, 78:913-934.

14. Keppel KG, Pearcy JN, Wagener DK: Trends in racial and ethnic-specific rates for the health status indicators: United States, 1990-98. Heal People 2000 Stat Notes Natl Cent Heal Stat 2002:1-16.

15. Asada Y: Assessment of the health of Americans: the average healthrelated quality of life and its inequality across individuals and groups. Popul Heal Metrics 2005, 3:7.

16. Kindig DA, Cheng ER: Even as mortality fell in most US counties, female mortality nonetheless rose in 42.8 Percent of counties from 1992 to 2006. Health Aff (Millwood) 2013, 32:451-458.

17. Srebotnjak T, Mokdad AH, Murray CJ: A novel framework for validating and applying standardized small area measurement strategies. Popul Heal Metrics 2010, 8:26

18. Cancer Facts and Figures: Cancer Facts and Figures, 2010. Atlanta, GA: American Cancer Society: 2010

19. Preston $\mathrm{SH}$, Wang $\mathrm{H}$ : Sex mortality differences in the United states: the role of cohort smoking patterns. Demography 2006, 43:631-646.

20. Pampel FC: Declining sex differences in mortality from lung cancer in high-income nations. Demography 2003, 40:45-65.

21. Dwyer-Lindgren L, Freedman G, Engell R, Fleming T, Lim SS, Mokdad AH, Christopher MJL: Prevalence of physical activity in US counties 2001-2011: a road Map for action. Population Health Metrics, 11:7.

22. Flegal KMCM: Prevalence and trends in obesity among us adults, 1999-2000. JAMA 2002, 288:1723-1727.

23. Signs, Vital: "State-specific Obesity Prevalence Among Adults - United States, 2009." Morbidity and Mortality Weekly Report.; 2010:951-955.

24. Winkleby MA, Jatulis DE, Frank E, Fortmann SP: Socioeconomic status and health: how education, income, and occupation contribute to risk factors for cardiovascular disease. Am J Public Health 1992, 82:816-820.

25. Sudano JJ, Baker DW: Explaining US racial/ethnic disparities in health declines and mortality in late middle age: the roles of socioeconomic status, health behaviors, and health insurance. Soc Sci Med 2006, 62:909-922.

26. Caldwell JC: Education as a factor in mortality decline an examination of nigerian data. Popul Stud 1979, 33:395-413.

27. Gakidou E, Cowling K, Lozano R, Murray CJ: Increased educational attainment and its effect on child mortality in 175 countries between 1970 and 2009: a systematic analysis. Lancet 2010, 376:959-974.

28. Cutler DM, Lleras-Muney A: Education and Health: Evaluating Theories and Evidence. Working Paper. Cambridge, MA: National Bureau of Economic Research; 2006.

29. Lynch SM: Cohort and life-course patterns in the relationship between education and health: A hierarchical approach. Demography 2003, 40:309-331.

30. Hobcraft J: Women's education, child welfare and child survival: a review of the evidence. Health Transit Rev 1993, 3:159-175.

31. Woolf SH, Laudan A (Eds): Panel on Understanding Cross-National Health Differences Among High-Income Countries; Committee on Population; Division of Behavioral and Social Sciences and Education; National Research Council; Board on Population Health and Public Health Practice; Institute of Medicine: U.S. Health in International Perspective: Shorter Lives, Poorer Health. Washington, D.C: The National Academies Press; 2013.

32. Ayanian JZ, Kohler BA, Abe T, Epstein AM: The relation between health insurance coverage and clinical outcomes among women with breast cancer. N Engl J Med 1993, 329:326-331.

33. Brook RH, Ware JE, Rogers WH, Keeler EB, Davies AR, Donald CA, Goldberg GA, Lohr KN, Masthay PC, Newhouse JP: Does free care improve Adults' health? N Engl J Med 1983, 309:1426-1434.

34. Young PL, Leigh Anne O, Michael McGinnis J: Roundtable on Evidence-Based Medicine; Institute of Medicine: Value in Health Care: Accounting for Cost, Quality, Safety, Outcomes, and Innovation: Workshop Summary. Washington, D.C: The National Academies Press; 2010.

35. Olives C, Myerson R, Mokdad AH, Murray CLL, Lim SS: Prevalence, awareness, treatment, and control of hypertension in United states counties, 2001-2009. Plos One 2013, 8:e60308. 
36. Lim SS, Vos T, Flaxman AD, Danaei G, Shibuya K, Adair-Rohani H, AIMazroa MA, Amann M, Anderson HR, Andrews KG, Aryee M, Atkinson C, Bacchus L, Bahalim AN, Balakrishnan K, Balmes J, Barker-Collo S, Baxter A, Bell ML, Blore JD, Blyth F, Bonner C, Borges G, Bourne R, Boussinesq M, Brauer M, Brooks P, Bruce NG, Brunekreef B, Bryan-Hancock $C$, et al: A comparative risk assessment of burden of disease and injury attributable to 67 risk factors and risk factor clusters in 21 regions, 1990-2010: a systematic analysis for the global burden of disease study 2010. Lancet 2012 380:2224-2260.

37. Danaei G, Rimm EB, Oza S, Kulkarni SC, Murray CJL, Ezzati M: The promise of prevention: the effects of four preventable risk factors on national life expectancy and life expectancy disparities by race and county in the United states. Plos Med 2010, 7:e1000248.

38. Galuska DA, Will JC, Serdula MK, Ford ES: Are health care professionals advising obese patients to lose weight? Jama J Am Med Assoc 1999, 282:1576-1578.

39. Denny $\mathrm{CH}$, Serdula MK, Holtzman D, Nelson DE: Physician advice about smoking and drinking: are U.S. adults being informed? Am J Prev Med 2003, 24:71-74.

40. Schoen C, Osborn R, Doty MM, Bishop M, Peugh J, Murukutla N: Toward higher-performance health systems: adults' health care experiences in seven countries, 2007. Health Aff (Millwood) 2007, 26:w717-w734.

41. Prevention Agenda: Toward the Healthiest State. http://www.health.ny.gov/ prevention/prevention_agenda/physical_activity_and_nutrition/.

42. Lewin S, Dick J, Pond P, Zwarenstein M, Aja GN, van Wyk BE, BoschCapblanch X, Patrick M: Lay health workers in primary and community health care. In Cochrane Database Syst Rev. Edited by The Cochrane Collaboration, Lewin S. Chichester, UK: John Wiley \& Sons, Ltd; 2005.

43. Jacobson Vann JC, Szilagyi P: Patient reminder and recall systems to improve immunization rates. In Cochrane Database Syst Rev. Edited by The Cochrane Collaboration, Jacobson Vann JC. Chichester, UK: John Wiley \& Sons, Ltd; 2005.

44. Jaén CR, Mcllvain H, Pol L, Phillips RL Jr, Flocke S, Crabtree BF: Tailoring tobacco counseling to the competing demands in the clinical encounter. J Fam Pract 2001, 50:859-863.

45. Crabtree BF, Miller WL, Tallia AF, Cohen DJ, DiCicco-Bloom B, Mcllvain HE, Aita VA, Scott JG, Gregory PB, Stange KC, McDaniel RR: Delivery of clinical preventive services in family medicine offices. Ann Fam Med 2005, 3:430-435.

46. Goldstein MG, Whitlock EP, DePue J: Multiple behavioral risk factor interventions in primary care: Summary of research evidence. Am J Prev Med 2004, 27(2, Supplement):61-79.

47. Congdon P: Estimating life expectancies for US small areas: a regression framework. J Geogr Syst:1-18.

doi:10.1186/1478-7954-11-8

Cite this article as: Wang et al:: Left behind: widening disparities for males and females in US county life expectancy, 1985-2010. Population Health Metrics 2013 11:8.

\section{Submit your next manuscript to BioMed Central and take full advantage of:}

- Convenient online submission

- Thorough peer review

- No space constraints or color figure charges

- Immediate publication on acceptance

- Inclusion in PubMed, CAS, Scopus and Google Scholar

- Research which is freely available for redistribution 